\title{
Pengaruh Kepuasan Kerja Terhadap Motivasi Kerja Pegawai Kelurahan
}

\author{
${ }^{1}$ Irawadi Siregar, ${ }^{2}$ Mhd. Ikhwanda Nawawi, ${ }^{3}$ Julius Partogi Haloho, ${ }^{4}$ Rahmat Tarihoran \\ ${ }^{1-4}$ Program Magister Manajemen, Fakultas Ekonomi, Universitas Islam Sumatera Utara
}

Article history

Received: 12 Jan 2021

Revised: 20 Feb 2021

Accepted: 02 Mar 2021

*Corresponding Author: Irawadi Siregar, Program Studi Magister Manajemen, Fakultas Ekonomi,

Universitas Islam Sumatera

Utara

Email:

bungarosarihtb@gmail.co

$\underline{\mathrm{m}}$

\begin{abstract}
Abstrak: Penelitian ini untuk menganalisis pengaruh kepuasan kerja terhadap motivasi kerja pegawai Kelurahan. Pengumpulan data dalam penelitian ini menggunakan metode kuantitatif. Kuesioner disebar melalui google form ke grup whats up pegawai Kelurahan Tanjung Rejo yang berjumlah 35 orang dan yang mengisi kuesioner sebanyak 33 orang. Metode analisis data yang digunakan dalam penelitian ini adalah adalah analisis jalur (path analysis) dengan menggunakan SPSS 23. Kepuasan kerja pegawai Kelurahan Tanjung Rejo juga ternyata terdapat kepuasan pegawai Kelurahan Tanjung Rejo secara positif di mana meningkatnya kepuasan kerja pegawai akan meningkatkan motivasi pegawai.
\end{abstract}

Kata Kunci : Pengaruh, Kepuasan Kerja, Motivasi Kerja, Pegawai Kelurahan

\section{PENDAHULUAN}

Fungsi pemerintah yang utama adalah menyelenggarakan pelayanan umum sebagai wujud dari tugas umum pemerintahan untuk mewujudkan kesejahteraan masyarakat. Seiring dengan hal tersebut pembinaan birokrasi melalui aparatur negara dilakukan secara terus menerus agar dapat menjadi alat yang efisien dan efektif, bersih dan berwibawa sehingga mampu menjalankan tugas-tugas umum pemerintah maupun untuk menggerakkan pembangunan secara lancar dengan dilandasi semangat dan sikap pengabdian terhadap masyarakat.

Hakikat dari pelaksanaan tugas dan fungsi kelurahan adalah untuk mengukur sampai sejauh mana kemampuan Kelurahan dalam melaksanakan pelayanan kepada masyarakat pada seksi sekretariat, tata pemerintahan, pembangunan, ketentraman dan ketertiban umum atas dasar kekuatan dan kemampuan kelurahan itu sendiri dengan memanfaatkan segenap potensi yang dimilikinya, baik potensi sumber daya alam, sumber daya manusia, maupun sumber sumber lainnya yang dapat mendukung kelancaran pelaksanaan tugas dan fungsi kelurahan tersebut sehingga implementasi tugas dan fungsi kelurahan akan lebih cepat terwujud.

Banyak faktor yang sangat menentukan keberhasilan pelaksanaan tugas dan fungsi kelurahan, salah satu faktor yang sangat menentukan adalah faktor sumber daya manusia yang ada di Kelurahan, baik dari segi kuantitas atau jumlahnya maupun dari segi kualitas atau mutunya. Guna mencapai tujuan yang ditetapkan maka Kelurahan Tanjung Rejo harus mampu meningkatkan motivasi kerja pegawai sehingga akan berdampak pada Organizational Citizenship Behaviour (OCB) pegawai.

Posisi pegawai Kelurahan Tanjung Rejo adalah sebagai garda terdepan dan sentral terlaksananya Organizational Citizenship Behaviour. Organizational Citizenship Behaviour pegawai memerlukan adanya totalitas, dedikasi, maupun loyalitas sebagai seorang pelayan administrasi bagi masyarakat atau stakeholders terkait. Menurut Handoko (2000) motivasi merupakan hal terpenting dalam Organizational Citizenship Behaviour dan perhatian Sumber 
Daya Manusia (SDM) lainnya berhubungan dengan motivasi tersebut. Seorang pegawai yang mempunyai motivasi kerja rendah biasanya akan mengalami kesulitan dalam melaksanakan tugas dan pekerjannya sehingga akan menyerah pada keadaan daripada berusaha untuk mengatasinya.

Menjadi pegawai tanpa motivasi kerja akan membuat pegawai malas bekerja, pegawai cepat merasa jenuh karena tidak adanya unsur pendorong. Motivasi mempersoalkan bagaimana caranya gairah kerja pegawai agar pegawai mau dan mampu bekerja keras dengan menyumbangkan segenap kemampuan, pikiran, keterampilan untuk mewujudkan tujuan organisasi. Pegawai yang menjadi seorang tenaga administrasi harus punya motivasi untuk melayani stakeholders terkait.

Selanjutnya faktor yang diduga dapat mempengaruhi Organizational Citizenship Behaviour adalah kepuasan kerja. Kepuasan kerja menurut Kreitner (2005) adalah suatu efektifitas atau respon emosional terhadap aspek pekerjaan. Dalam rangka memahami kepuasan kerja pegawai, maka seorang pemimpin harus memahami karakter masing-masing bawahan. Dengan memahami karakter individu maka akan dapat ditentukan pekerjaan yang sesuai dengan karakter masing-masing individu. Apabila hal tersebut terwujud maka kepuasan kerja akan dapat tercapai, sehingga motivasi kerjanya menjadi lebih baik. Dengan kepuasan kerja yang tinggi pada setiap diri pegawai akan mendorong para pegawai untuk memberikan komitmen mereka pada organisasi, dengaan komitmen yang ada secara tidak langsung akan memberikan dorongan terciptanya Organizational Citizenship Behaviour. Fenomena tentang kepuasan kerja di Kantor Lurah Tanjung Rejo menunjukkan bahwa kepuasan kerja pegawai belum maksimal, hal ini dapat terlihat dari tingkat pelayanan aparatur Kelurahan belum dikategorikan baik. Selain dari pada itu masih ada aparat Kelurahan yang sulit dijumpai pada waktu jam kerja, sehingga masyarakat yang berurusan merasa kecewa. Hal ini mungkin disebabkan oleh gaji aparat Kelurahan yang masih kecil atau fasilitas kerja yang ada masih kurang mendukung terciptanya Organizational Citizenship Behaviour pegawai Kelurahan Tanjung Rejo.

\section{METODE PENELITIAN}

Pengumpulan data dalam penelitian ini menggunakan metode kuantitatif. Kuesioner disebar melalui google form ke grup whats up pegawai Kelurahan Tanjung Rejo yang berjumlah 35 orang dan yang mengisi kuesioner sebanyak 33 orang. Metode analisis data yang digunakan dalam penelitian ini adalah adalah analisis jalur (path analysis) dengan menggunakan SPSS 23. Pada saat penelitian, peneliti menentukan populasi yang ingin diteliti sesuai dengan tujuan penelitian. Karena populasi adalah wilayah generalisasi yang terdiri atas obyek/subjek yang mempunyai kuantitas dan disiplin tertentu yang ditetapkan oleh peneliti untuk dipelajari dan kemudian ditarik kesimpulannya (Sugiyono, 2013). Jadi populasi bukan hanya orang tetapi juga benda-benda alam yang lain. Populasi juga bukan sekedar jumlah yang ada pada objek/subjek yang dipelajari, tetapi meliputi seluruh disiplin, sifat yang dimiliki objek/subjek pada pegawai Kelurahan Tanjung Rejo.

\section{Teknik Analisis Data}

\section{Analisis Jalur}


Metode analisis data yang digunakan dalam penelitian ini adalah analisis jalur. Metode yang digunakan dalam penelitian ini adalah analisis jalur (path analysis) dengan menggunakan SPSS 23. Analisis jalur (path analysis) digunakan untuk mengetahui hubungan sebab akibat, dengan tujuan menerangkan pengaruh langsung atau tidak langsung antar variabel eksogen dengan variabel endogen. Dalam penelitian ini, analisis jalur digunakan untuk melihat ada pengaruh fasilitas kerja dan kepuasan kerja terhadap motivasi kerja serta dampaknya pada OCB pegawai Kelurahan Tanjung Rejo.

Menurut Sugiyono (2013) analisis jalur adalah bagian dari model regresi yang dapat digunakan untuk menganalisi hubungan sebab akibat antar satu variabel dengan variabel lainnya. Analisis jalur digunakan dengan menggunakan korelasi, regresi dan jalur sehingga dapat diketahui untuk sampai pada variabel intervening. Adapun pendapat dari Riduwan dan Kuncoro (2014) model analisis jalur digunakan untuk menganalisis pola hubungan antar variabel dengan tujuan untuk mengetahui pengaruh langsung maupun tidak langsung seperangkat variabel independen (eksogen) terhadap variabel dependen (endogen).

\section{Uji Validitas dan Uji Reliabilitas}

Uji validitas digunakan untuk mengukur sah atau valid tidaknya suatu kuesioner. Suatu kuesioner dikatakan valid jika pertanyaan pada kuesioner mampu untuk mengungkap sesuatu yang akan diukur oleh kuesioner tersebut. Uji validitas dapat dilakukan dengan melihat korelasi antara skor masing-masing item dalam kuesioner dengan total skor yang ingin diukur, yaitu dengan menggunakan Coefficient Correlation Pearson dalam SPSS. Jika nilai signifikansi (P Value) $>0,05$, maka tidak terjadi hubungan yang signifikan. Sedangkan, apabila nilai signifikansi $(\mathrm{P}$ Value $)<0,05$, maka terjadi hubungan yang signifikan.

\section{Uji $\mathbf{R}^{2}$ (Koefisien Determinasi)}

Koefisien determinasi adalah data untuk mengetahui seberapa besar persentase pengaruh langsung variabel bebas yang semakin dekat hubungannya dengan variabel terikat atau dapat dikatakan bahwa penggunaan model tersebut bisa dibenarkan. Dari koefisien determinasi ini $\left(\mathrm{R}^{2}\right)$ dapat diperoleh suatu nilai untuk mengukur besarnya hubungan dari variabel $\mathrm{X}(1,2)$ terhadap Y1 kemudian $\mathrm{X}(1,2)$ dan Y1 terhadap Y2.

\section{Uji Hipotesis Secara Parsial (Uji-t)}

Uji ini digunakan untuk mengetahui signifikansi dari pengaruh variabel independen terhadap variabel dependen secara individual dan menganggap dependen yang lain konstan. Signifikansi pengaruh tersebut dapat diestimasi dengan membandingkan antara nilai $t_{\text {tabel }}$ dengan nilai thitung.

Apabila nilai thitung $>t_{\text {tabel }}$ maka variabel independen secara individual mempengaruhi variabel dependen, sebaliknya jika nilai $t_{\text {hitung }}<\mathrm{t}_{\text {tabel }}$ maka variabel independen secara individual tidak mempengaruhi variabel dependen.

$t_{\text {hitung }}>\mathrm{t}_{\text {tabel }}$ berarti $\mathrm{H}_{0}$ ditolak dan menerima $\mathrm{H}_{1}$

$\mathrm{t}_{\text {hitung }}<\mathrm{t}_{\text {tabel }}$ berarti $\mathrm{H}_{0}$ diterima dan menolak $\mathrm{H}_{1}$

Uji t juga bisa dilihat pada tingkat signifikansinya :

1) Jika tingkat signifikansi $<0,05$, maka $\mathrm{H}_{0}$ ditolak dan $\mathrm{H}_{1}$ diterima.

2) Jika tingkat signifikansi $>0,05$, maka $\mathrm{H}_{0}$ diterima dan $\mathrm{H}_{1}$ ditolak 


\section{Uji F (Uji Hipotesis Simultan)}

Uji F digunakan untuk menguji tingkat signifikan dari pengaruh variabel independent secara keseluruhan terhadap variabel dependent. Pada penelitian ini, peneliti mengajukan hipotesis dengan taraf nyata $\alpha=0,05$ sebagai berikut :

- $\quad$ H0 : $\rho z y x=0$, artinya tidak terdapat pengaruh Fasilitas Kerja (X1), kepuasan kerja (X2) terhadap OCB pegawai Kelurahan Tanjung Rejo (Y2) melalui variabel Motivasi kerja (Y1) secara simultan.

- H1 : $\rho z y x \neq 0$, artinya terdapat pengaruh Fasilitas Kerja (X1), kepuasan kerja (X2), terhadap OCB pegawai Kelurahan Tanjung Rejo (Y2) melalui variabel Motivasi kerja (Y1) secara simultan.

\section{HASIL DAN PEMBAHASAN}

\section{Analisis Data}

Kuesioner disebar melalui google form ke grup whats up pegawai Kelurahan Tanjung Rejo yang berjumlah 35 orang, dan pegawai yang mengisi kuesioner yakni 33 orang. Berdasarkan hasil estimasi pada tabel sebelumnya maka berikut ini hasil uji t statistik dari masing-masing variabel independen bahwa hasil pengujian dengan menggunakan program SPSS 24 diperoleh nilai t statistik untuk kepuasan kerja adalah 2,523 dan probabilitas 0,017. Sedangkan nilai t tabel untuk jumlah observasi sebanyak 40 dengan tingkat signifikansi 5\% dan derajat kebebasan $(\mathrm{dk})=40-4=37$ diperoleh 2,02619. Sehingga diperoleh bahwa tstatistik lebih besar dari t- tabel atau 2,523 > 2,02619, dan juga dapat dilihat pada nilai probabilitas lebih kecil dari tingkat signifikansi $(\alpha) 5 \%$ atau $0,017<0,05$ maka dapat diambil kesimpulan bahwa kepuasan kerja signifikan mempengaruhi motivasi kerja pegawai Kelurahan Tanjung Rejo dengan kesimpulan HO ditolak dan menerima Ha. Hal ini menyatakan bahwa kepuasan kerja memberikan pengaruh nyata terhadap motivasi kerja pegawai Tanjung Rejo dengan tingkat kepercayaan 95\% atau tingkat kesalahan 5\%.

Hasil pengujian dengan menggunakan program SPSS 24 diperoleh nilai t statistik untuk motivasi kerja adalah 2,942 dan probabilitas 0,006. Sedangkan nilai t tabel untuk jumlah observasi sebanyak 40 dengan tingkat signifikansi $5 \%$ dan derajat kebebasan $(\mathrm{dk})=$ $40-4=36$ diperoleh 2,02809. Sehingga diperoleh bahwa t-statistik lebih besar dari t- tabel atau 2,942>2,02809, dan juga dapat dilihat pada nilai probabilitas lebih kecil dari tingkat signifikansi $(\alpha) 5 \%$ atau $0,006<0,05$ maka dapat diambil kesimpulan bahwa motivasi kerja signifikan mempengaruhi Organizational Citizenship Behaviour pegawai Kelurahan Tanjung Rejo dengan kesimpulan H0 ditolak dan menerima Ha. Hal ini menyatakan bahwa motivasi kerja memberikan pengaruh nyata terhadap Organizational Citizenship Behaviour pegawai Kelurahan Tanjung Rejo dengan tingkat kepercayaan 95\% atau tingkat kesalahan 5\%.

Berdasarkan hasil uji t di atas dapat dilihat bahwa fasilitas kerja dan kepuasan kerja tidak berpengaruh signifikan terhadap mutu pelayanan secara parsial. Sedangkan variabel motivasi kerja berpengaruh signifikan terhadap mutu pelayanan secara parsial.

\section{1) Analisis Tahap Dua}

Pada analisis tahap 2 ini akan fasilitas kerja dan kepuasan kerja terhadap motivasi kerja pegawai Kelurahan Tanjung Rejo dengan persamaan sebagai berikut :

$$
\mathrm{Y}_{1}=\mathrm{a}+\mathrm{b} 1 \mathrm{X} 1+\mathrm{b} 2 \mathrm{X} 2+\mathrm{e} 1
$$


a) Uji Determinasi

Tabel 1. Koefisien Determinasi Tahap 2

Model Summary

\begin{tabular}{|l|r|r|r|r|}
\hline Model & \multicolumn{1}{|c|}{$\mathrm{R}$} & R Square & \multicolumn{1}{c|}{$\begin{array}{c}\text { Adjusted R } \\
\text { Square }\end{array}$} & $\begin{array}{c}\text { Std. Error of } \\
\text { the Estimate }\end{array}$ \\
\hline 1 & $.774^{\mathrm{a}}$ & .599 & .572 & 2.17654 \\
\hline
\end{tabular}

a. Predictors: (Constant), Kualitas Kerja, Fasilitas Kerja

b. Dependent Variable: Motivasi Kerja

Sumber: Data diolah, 2020

Dari tabel di atas terlihat bahwa pada model regresi linier berganda untuk persamaan pertama, yaitu : $\mathbf{Y}_{\mathbf{1}}=\mathbf{a}+\mathbf{b} \mathbf{1 X 1}+\mathbf{b} \mathbf{2 X 2}+\mathbf{e 1}$ menunjukkan nilai koefisien determinasi sebesar 0,599 yang memiliki arti bahwa pengaruh variabel fasilitas kerja dan kepuasan kerja terhadap motivasi kerja pegawai Kelurahan Tanjung Rejo adalah sebesar 59,9\% sedangkan sisanya 40,1\% dijelaskan oleh pengaruh faktor-faktor lain.

b) Uji Simultan

Tabel 2. Uji Simultan Tahap 2

ANOVA $^{\mathrm{a}}$

\begin{tabular}{|ll|r|r|r|r|r|}
\hline \multicolumn{2}{|l|}{ Model } & \multicolumn{1}{|c|}{$\begin{array}{l}\text { Sum of } \\
\text { Squares }\end{array}$} & df & Mean Square & F & Sig. \\
\hline 1 & Regression & 211.941 & 2 & 105.970 & 22.369 & $.000^{\mathrm{b}}$ \\
& Residual & 142.120 & 30 & 4.737 & & \\
& Total & 354.061 & 32 & & & \\
\hline
\end{tabular}

a. Dependent Variable: Motivasi Kerja

b. Predictors: (Constant), Kepuasan Kerja, Fasilitas Kerja

Sumber: Data diolah, 2020

Berdasarkan hasil pengujian di atas dapat dilihat nilai F-hitung adalah 22,369 dengan nilai signifikansi adalah 0,000000. Nilai F-tabel untuk jumlah obeservasi sebanyak 40 dengan tingkat alpha 5\% dan $\mathrm{k}$ atau jumlah seluruh variabel baik variabel independen dan dependen adalah 4 , maka nilai $\mathrm{N} 1=\mathrm{k}-1=3-1=2, \mathrm{~N} 2=\mathrm{n}-\mathrm{k}=40-3=37$ adalah 2,86. Sehingga diperoleh bahwa F-hitung lebih besar dari F-tabel atau 22,369>2,86 dan juga dapat dilihat pada nilai probabilitas lebih kecil dari tingkat signifikansi $(\alpha) 5 \%$ atau $0,000000<$ 0,05 maka dapat diambil kesimpulan bahwa variabel variabel fasilitas kerja dan kepuasan kerja secara simultan (bersama-sama) mempengaruhi motivasi kerja pegawai Kelurahan Tanjung Rejo dengan kesimpulan H0 ditolak. 


\section{Uji Parsial}

Tabel 3. Uji Parsial Tahap 2

\begin{tabular}{|c|c|c|c|c|c|}
\hline \multirow[b]{2}{*}{ Model } & \multicolumn{2}{|c|}{ Unstandardized Coefficients } & \multirow{2}{*}{$\begin{array}{c}\begin{array}{c}\text { Standardized } \\
\text { Coefficients }\end{array} \\
\text { Beta }\end{array}$} & \multirow[b]{2}{*}{$\mathrm{t}$} & \multirow[b]{2}{*}{ Sig. } \\
\hline & $\mathrm{B}$ & Std. Error & & & \\
\hline $1 \quad$ (Constant $)$ & 14.040 & 3.567 & & 3.936 & .000 \\
\hline Fasilitas Kerja & .291 & .137 & .376 & 2.119 & .043 \\
\hline Kepuasan & 230 & 124 & 410 & 200 & 017 \\
\hline Kerja & .539 & .134 & . .440 & 2.020 & (011 \\
\hline
\end{tabular}

a. Dependent Variable: Motivasi Kerja

Sumber: Data diolah, 2020

Uji t untuk menguji signifikansi setiap variabel independen, variabel variabel fasilitas kerja dan kepuasan kerja secara parsial (individual) terhadap motivasi kerja pegawai Kelurahan Tanjung Rejo. Dalam hal ini, dasar pengambilan keputusan adalah dengan membandingkan t-tabel dengan $t$ hitung. Data di atas diketahui dk (derajat kebebasan) $=40$ $3=37$ dengan taraf kepercayaan $\alpha=0,05$ maka t-tabel sebesar 2,02619. Pedoman yang digunakan untuk menerima atau menolak hipotesis yaitu:

- Ha diterima jika t-hitung > t-tabel atau nilai p-value pada kolom sig. $<$ level of significant $(\alpha) 5 \%$ berarti variabel independen memiliki pengaruh terhadap variabel dependen.

- Ho diterima jika t-hitung < t-tabel atau nilai p-value pada kolom sig.> level of significant $(\alpha) 5 \%$ berarti variabel independen tidak memiliki pengaruh terhadap variabel dependen

Kepuasan kerja pegawai Kelurahan Tanjung Rejo juga ternyata dapat memotivasi pegawai Kelurahan Tanjung Rejo secara positif di mana meningkatnya kepuasan kerja pegawai akan meningkatkan motivasi pegawai dalam bekerja sehingga OCB juga ikut meningkat secara tidak langsung. Kepuasan terhadap gaji yang tinggi, kepuasan akan reward atau bonus yang didapat saat hasil kinerja tinggi, penempatan pegawai yang sesuai dengan keterampilannya, jenis pekerjaan yang beragam dan tingkat kesulitan yang membuat pegawai merasa tertantang akan membuat motivasi pegawai meningkat. Tidak hanya itu, kesempatan berkarir yang sama oleh setiap pegawai, nyaman bekerja dengan lingkungan yang menyenangkan dan transparansi mempertahankan dan mengembangkan jalur karir juga meningkatkan motivasi pegawai kelurahan Tanjung Rejo dalam bekerja.

\section{KESIMPULAN}

Disimpulkan bahwa kepuasan kerja pegawai Kelurahan Tanjung Rejo juga ternyata dapat memotivasi pegawai Kelurahan Tanjung Rejo secara positif di mana meningkatnya kepuasan kerja pegawai akan meningkatkan motivasi pegawai dalam bekerja. Sehingga kepuasan juga ikut meningkat secara tidak langsung. Kepuasan kerja berpengaruh positif dan 
signifikan terhadap motivasi kerja walaupun tidak secara langsung terhadap pegawai kelurahan Tanjung Rejo.

\section{DAFTAR PUSTAKA}

Handoko, T. H. 2000. Manajemen Personalia Dan Manajemen Sumber Daya Manusia. Yogyakarta: BPFE.

Kreitner, R., \& Kinicki, A. 2005. Perilaku Organisasi. Jakarta: Salemba Empat.

Sugiyono. 2006. Statistika Untuk Penelitian. Bandung : Alfabeta.

Triton, PB. 2005. Paradigma Baru Manajemen Sumber Daya Manusia, Tugu Yogyakarta. 